\title{
Investigation of deep level defects in copper irradiated bipolar junction transistor
}

\author{
K.V. Madhu ${ }^{\mathrm{a}}$, Ravi Kumar ${ }^{\mathrm{b}}$, M. Ravindra ${ }^{\mathrm{c}}$, R. Damle ${ }^{\mathrm{a}, *}$ \\ ${ }^{a}$ Department of Physics, Jnanabharati, Bangalore University, Bangalore 560 056, India \\ ${ }^{\mathrm{b}}$ Inter University Accelerator Center, Aruna Asaf Ali Marg, New Delhi 110 067, India \\ ' Components Division, ICG, ISRO Satellite Centre, Bangalore 560 017, India
}

\section{A R T I C L E I N F O}

\section{Article history:}

Received 13 September 2007

Received in revised form 29 May 2008

Accepted 4 June 2008

Available online 16 July 2008

The review of this paper was arranged by Prof. S. Cristoloveanu

\section{PACS:}

71.55.- $\mathrm{i}$

72.20.Jv

78.70.- $\mathrm{g}$

61.82.Fk

Keywords:

Bipolar junction transistor

Deep Level Transient Spectroscopy

Deep level defects

Shockley Read Hall recombination

Isochronal annealing

\begin{abstract}
A B S T R A C T

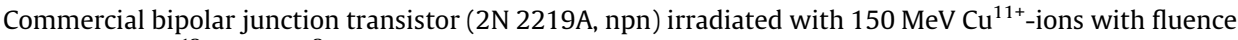
of the order $10^{12}$ ions $\mathrm{cm}^{-2}$, is studied for radiation induced gain degradation and deep level defects. $I-V$ measurements are made to study the gain degradation as a function of ion fluence. The properties such as activation energy, trap concentration and capture cross-section of deep levels are studied by deep level transient spectroscopy (DLTS). Minority carrier trap levels with energies ranging from $E_{\mathrm{C}}-0.164 \mathrm{eV}$ to $E_{\mathrm{C}}-0.695 \mathrm{eV}$ are observed in the base-collector junction of the transistor. Majority carrier trap levels are also observed with energies ranging from $E_{\mathrm{V}}+0.203 \mathrm{eV}$ to $E_{\mathrm{V}}+0.526 \mathrm{eV}$. The irradiated transistor is subjected to isothermal and isochronal annealing. The defects are seen to anneal above $350{ }^{\circ} \mathrm{C}$. The defects generated in the base region of the transistor by displacement damage appear to be responsible for transistor gain degradation.
\end{abstract}

(c) 2008 Elsevier Ltd. All rights reserved.

\section{Introduction}

Bipolar junction transistors (BJTs) are still being extensively used in space and other radiation rich environments. These devices are sensitive to high energy particle irradiation. Considerable amount of data are available on the radiation effects of $\gamma$-rays, fast neutrons, electrons and protons on semiconductor devices [1-5]. However, there appears to be rather little work on heavy ion induced effects and consequent characterization of defects by DLTS technique. Deep level defect monitoring plays an important role in designing a semiconductor device suitably for various applications. Thus a study of radiation induced effects in semiconductor devices is important to observe changes in electrical characteristics and to get basic information regarding the generation and annihilation of defects.

Exposure of semiconductor devices to high energy particle radiation is known to generate variety of defects. The nature of these defects generated by irradiation process depends on the properties

\footnotetext{
* Corresponding author. Tel.: +91 0802296 1483; fax: +91 08023219295

E-mail address: ramkrishnadamle@bub.ernet.in (R. Damle).
}

of target as well as impinging high energy particle. To investigate these deep level defects several techniques are in practice. Deep level transient spectroscopy (DLTS) is now an established technique for detecting and characterizing variety of defects in semiconductor devices. DLTS is a high frequency capacitance transient thermal scanning method useful in observing a wide variety of traps in semiconductor devices [6].

The BJT used in the present study has been thoroughly studied in our earlier work for $24 \mathrm{MeV}$ protons, $8 \mathrm{MeV}$ electrons and ${ }^{60} \mathrm{Co}$ $\gamma$-rays induced effects [7-9]. A DLTS study of deep level defects in Li-ion irradiated transistor (chosen from the same batch) is also reported earlier [10].

\section{Experimental details}

Commercial BJT (2N 2219A, npn) manufactured in an indigenous technology from Continental Device India Ltd. (CDIL) has been selected for the present study. This device is a switching transistor with standard configuration (base thickness is $2.0 \mu \mathrm{m}$ and oxide thickness is $1.2 \mu \mathrm{m}$ ) suitable for low and high frequency 
operation. Decapped transistor is exposed to $150 \mathrm{MeV} \mathrm{Cu}^{1{ }^{1+}}$-ions using 15 UD $16 \mathrm{MV}$ pelletron Tandem Van de Graff accelerator facility at Inter-University Accelerator Centre, New Delhi. The transistor in the biased condition (CE mode) is irradiated by $\mathrm{Cu}^{1{ }^{1+}}$-ions with three different fluences $3 \times 10^{11}$ ions $\mathrm{cm}^{-2}$, $1 \times 10^{12}$ ions $\mathrm{cm}^{-2}$ and $1 \times 10^{13}$ ions $\mathrm{cm}^{-2}$. During irradiation, the target chamber is maintained at room temperature $(300 \mathrm{~K})$ and low pressure $\left(7.5 \times 10^{-9} \mathrm{Torr}\right)$. The ion fluences are calculated by measuring the ion beam current and irradiation time. The ion beam current is fixed at $\sim 1$ particle nano ampere ( $\mathrm{pnA}$ ). Output characteristics of the transistor are studied at a constant base current $\left(I_{\mathrm{B}}\right)$ of $50 \mu \mathrm{A}$. The collector voltage $\left(V_{\mathrm{CE}}\right)$ is varied from $-0.1 \mathrm{~V}$ to $1.5 \mathrm{~V}$ in steps of $0.01 \mathrm{~V}$. Gummel plots are acquired by varying base emitter voltage $\left(V_{\mathrm{BE}}\right)$ from $0 \mathrm{~V}$ to $0.7 \mathrm{~V}$ in steps of $0.01 \mathrm{~V}$ at constant collector voltage $\left(V_{\mathrm{CE}}\right)$ of $5 \mathrm{~V}$.

DLTS spectra are recorded for both unirradiated transistor and three different transistors of the same batch (date code) exposed to $\mathrm{Cu}^{11+}$-ion for different fluences. The DLTS system (IMS-2000, $\mathrm{M} / \mathrm{s}$. Lab Equip, India) employed for the present study consists of a boxcar averager, a pulse generator, a thousand point digitizer, a voltage generator and a high speed capacitance meter. The pulse generator is capable of generating pulses of widths ranging from $100 \mathrm{~ns}$ to $10 \mathrm{~s}$. The pulse height could be programmed from $12 \mathrm{~V}$ to $+12 \mathrm{~V}$. The boxcar averager is capable of generating seven rate windows. The time constants can be varied from $1 \mathrm{~ms}$ to $2 \mathrm{~s}$. In the present study, DLTS spectra are recorded with a reverse bias of $5 \mathrm{~V}$ and pulse width of $19.2 \mathrm{~ms}$ applied to base-collector junction. The trap concentration, activation energy and capture crosssection of different deep levels are determined by DLTS spectra.

The transistors are subjected to isothermal and isochronal (30 min) annealing. The annealing temperature in the furnace can be maintained constant for several hours with an accuracy of $1^{\circ} \mathrm{C}$. During isochronal (30 $\mathrm{min}$ ) annealing, the temperature is varied from $100^{\circ} \mathrm{C}$ to $500^{\circ} \mathrm{C}$. During isothermal $\left(100^{\circ} \mathrm{C}\right)$ annealing, the annealing time is varied from $30 \mathrm{~min}$ to $480 \mathrm{~min}$. DLTS spectra are recorded at different stages of thermal annealing and the characteristics of several deep level defects are monitored.

\section{Results and discussion}

\subsection{I-V measurements}

In general, any disturbance of lattice periodicity in the bulk of the semiconductor may give rise to energy levels in the band

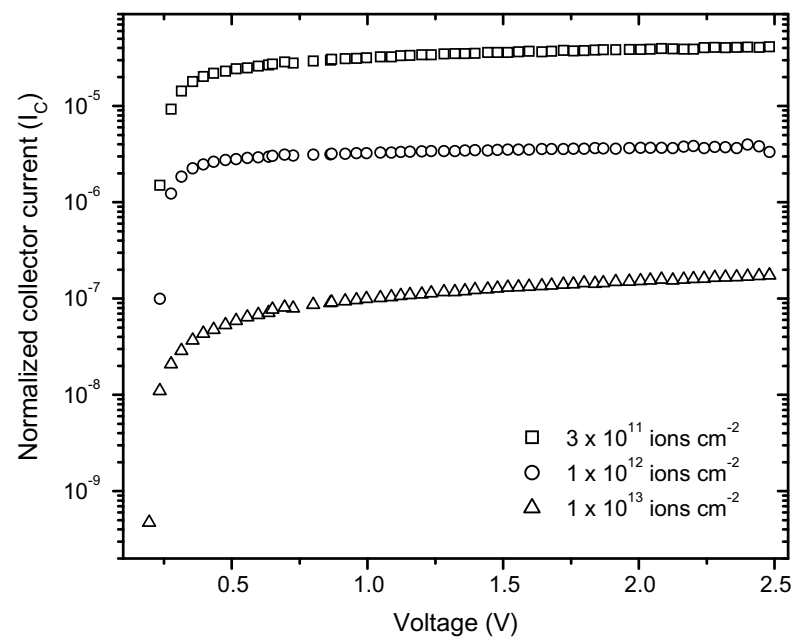

Fig. 1. Collector characteristics of $\mathrm{Cu}$-ion irradiated transistor for three different ion fluences (at constant $I_{\mathrm{B}}=50 \mu \mathrm{A}$ ).

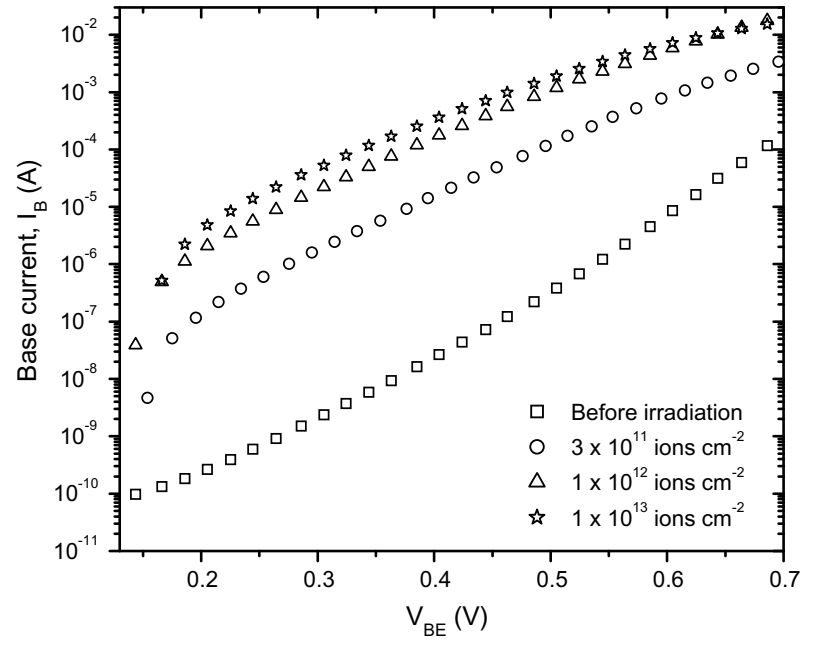

Fig. 2. Variation of $I_{\mathrm{B}}$ with $V_{\mathrm{BE}}$ for three different ion fluences (at constant $V_{\mathrm{CE}}=5 \mathrm{~V}$ ).

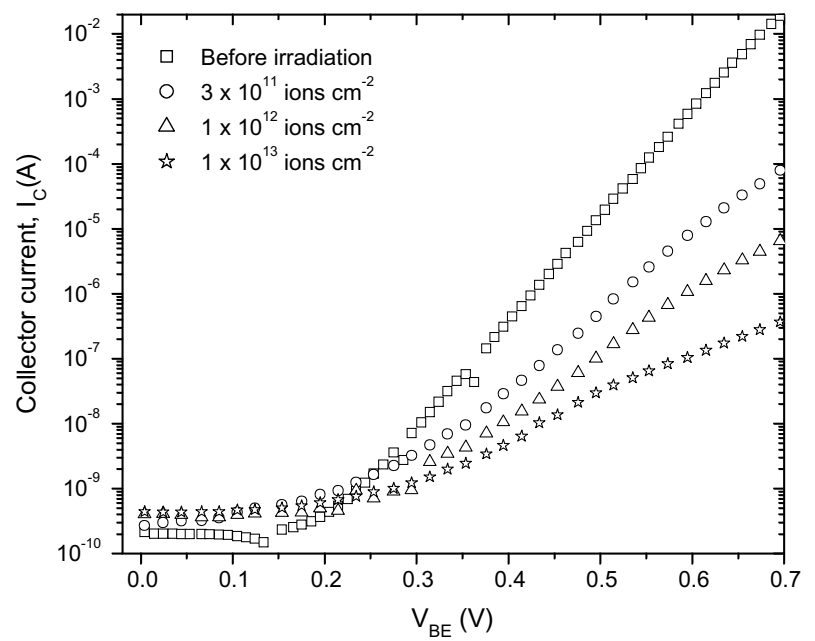

Fig. 3. Variation of $I_{\mathrm{C}}$ with $V_{\mathrm{BE}}$ for three different ion fluences (at constant $V_{\mathrm{CE}}=5 \mathrm{~V}$ ).

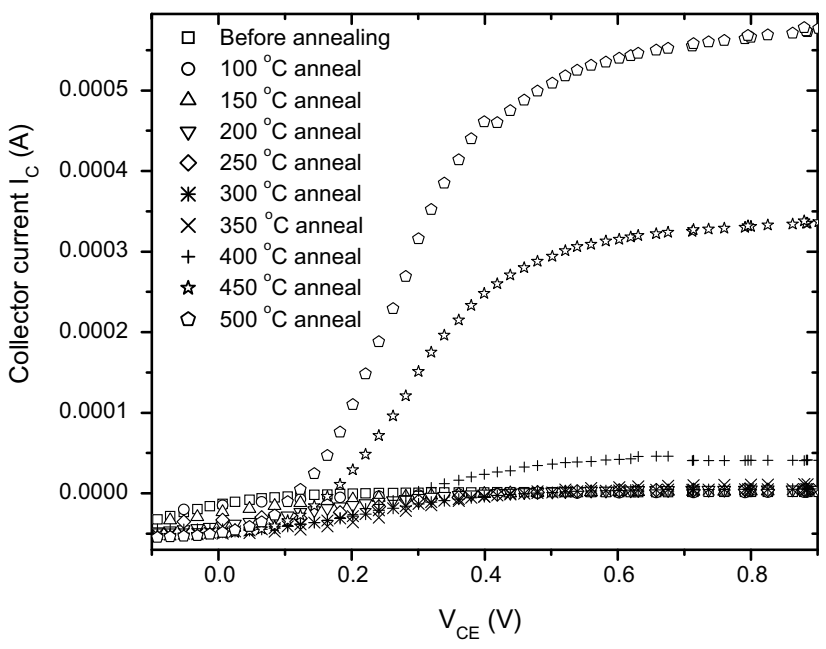

Fig. 4. Collector characteristics of the Cu-ion irradiated transistor at different isochronal annealing temperatures (at constant $I_{\mathrm{B}}=50 \mu \mathrm{A}$ ). 


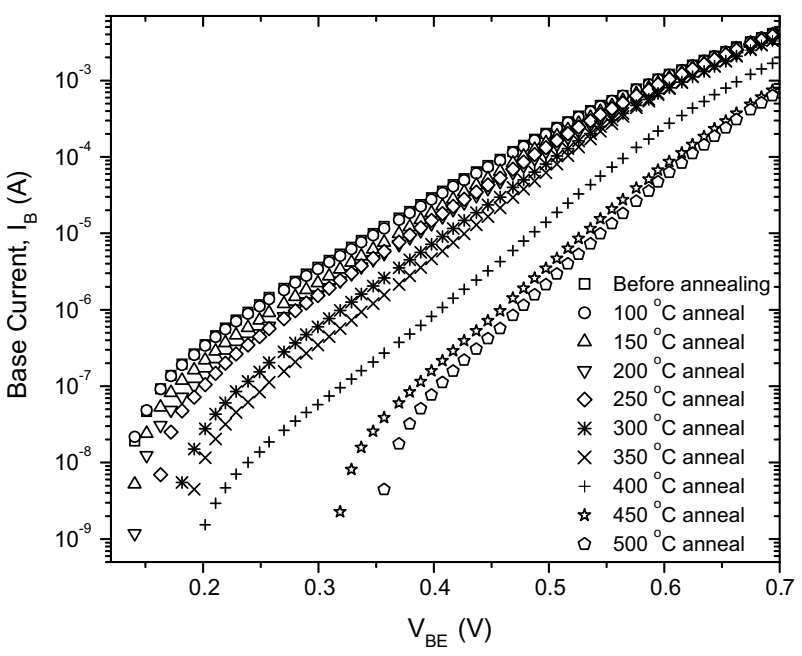

Fig. 5. Variation of $I_{\mathrm{B}}$ with $V_{\mathrm{BE}}$ at different isochronal annealing temperatures (at constant $V_{\mathrm{CE}}=5 \mathrm{~V}$ ).

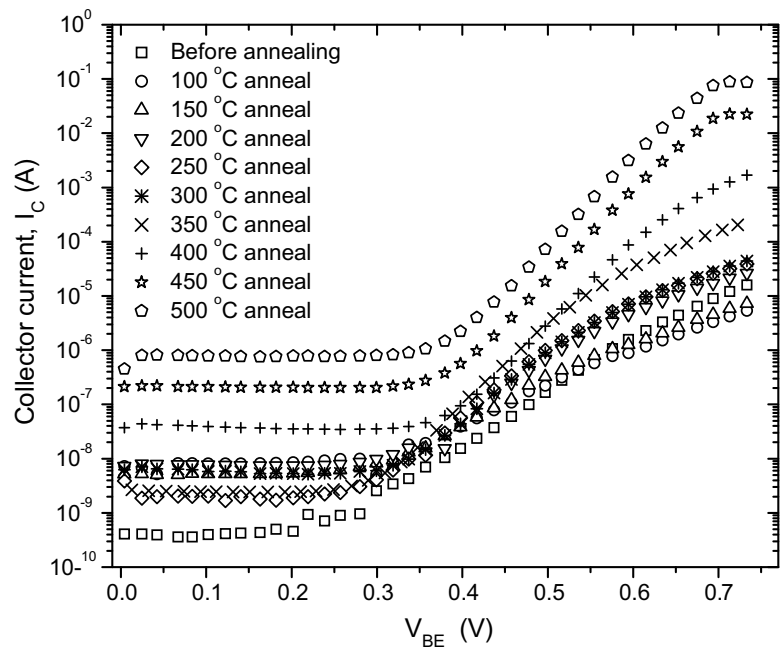

Fig. 6. Variation of $I_{\mathrm{C}}$ with $V_{\mathrm{BE}}$ at different isochronal annealing temperatures (at constant $V_{\mathrm{CE}}=5 \mathrm{~V}$ ).

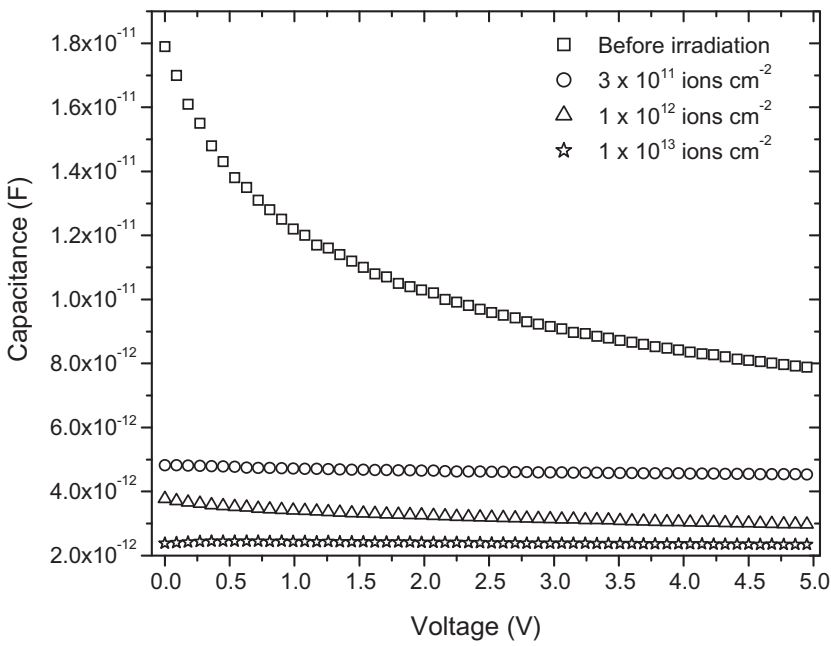

Fig. 7. $C-V$ characteristics of the $\mathrm{Cu}$-ion irradiated transistor for three different fluences. gap. Radiation induced defects may have such energy levels with them and these defects can have a major impact on the electrical characteristics of the transistor [11]. Fig. 1 exhibits the collector characteristics of the $\mathrm{Cu}$-ion irradiated transistor for three different fluences. This plot indicates that the collector current decreases with an increase in the ion fluence. Figs. 2 and 3 exhibit Gummel plots (variation of base current $I_{\mathrm{B}}$, collector current $I_{\mathrm{C}}$ with base



Fig. 8. $C-V$ characteristics of the $\mathrm{Cu}$-ion irradiated transistor at different isochronal annealing temperatures.

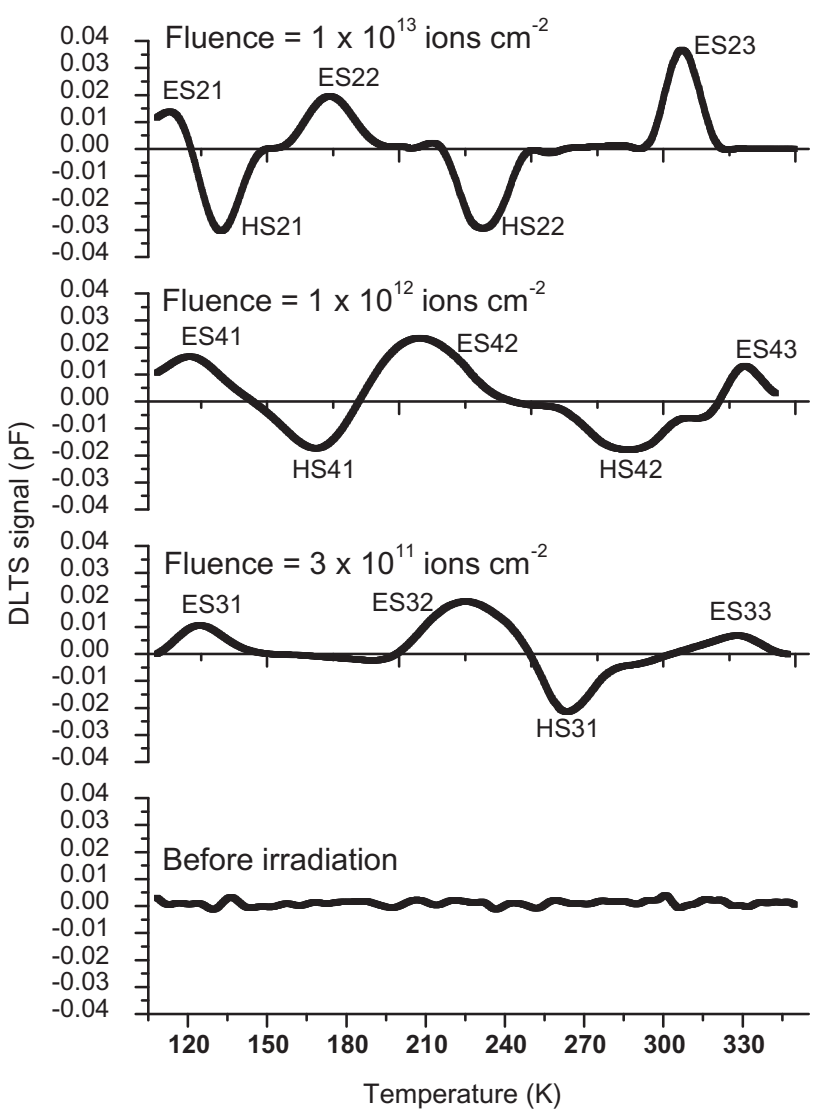

Fig. 9. DLTS spectra of Cu-ion irradiated transistor for three different fluences. Rate window is fixed at $127.9 \mathrm{~s}^{-1}$. 
voltage $V_{\mathrm{BE}}$ ) before and after irradiation. It is observed that the base current increases with ion fluence. However, the collector current decreases as the ion fluence increases. This increase in base current and decrease in collector current upon irradiation could be attributed to the increased recombination of charge carriers in the basecollector junction of the transistor.

One important aspect of characterization of BJTs for radiation induced effects is radiation induced gain degradation. The BJTs are found to be particularly vulnerable to ionizing radiation and the transistor gain degradation is the primary cause for parametric shifts and functional failures. The degradation of forward current gain of BJT when exposed to radiation is dependent largely on nature and energy of radiation and to some extent on the dose rate. It is well known that the degradation of the transistor can occur due to increased recombination in the base region due to displacement damage caused upon irradiation. The increased recombination in the neutral base leads to an increase in the base current which in turn results in a decrease in the collector current. When recombination centers are generated in the base region of the transistor, it leads to an increase in the base current by decreasing the minority carrier lifetime [12]. A decrease in the minority carrier lifetime will be reflected in the degradation of forward current gain of the transistor.

Fig. 4 shows the collector characteristics of the transistor irradiated with $1 \times 10^{12}$ ions $\mathrm{cm}^{-2}$ at different isochronal (30 min) annealing temperatures. The isochronal annealing clearly shows that there is a major recovery in the collector current above $400{ }^{\circ} \mathrm{C}$. Figs. 5 and 6 exhibit the variation of $I_{\mathrm{B}}$ and $I_{\mathrm{C}}$ as a function of $V_{\mathrm{BE}}$ at different isochronal ( $30 \mathrm{~min}$ ) annealing temperatures. It is found that while collector current increases, the base current decreases with an increase in annealing temperature.

\section{2. $C-V$ measurements}

Fig. 7 shows the capacitance-voltage $(C-V)$ characteristics of the base-collector junction of the transistor before and after irradiation. The plot shows that there is a considerable degradation in the $C-V$ characteristics of the transistor after irradiation. This would indicate that there is a partial loss of charge carriers in the base-collector junction of the transistor upon irradiation. This loss could be attributed to an increased recombination in the base-collector junction of the irradiated transistor. Fig. 8 shows the $C-V$ characteristics of the base-collector junction of the transistor irradiated with $1 \times 10^{12}$ ions $\mathrm{cm}^{-2}$ at different isochronal (30 min) annealing temperatures. The $C-V$ characteristics appear to improve after $350^{\circ} \mathrm{C}$ temperature.

\subsection{DLTS measurements}

In principle, irradiation by any ion can damage transistors through both ionization and displacement. Displacement damage is a bulk phenomenon which results in the generation of several
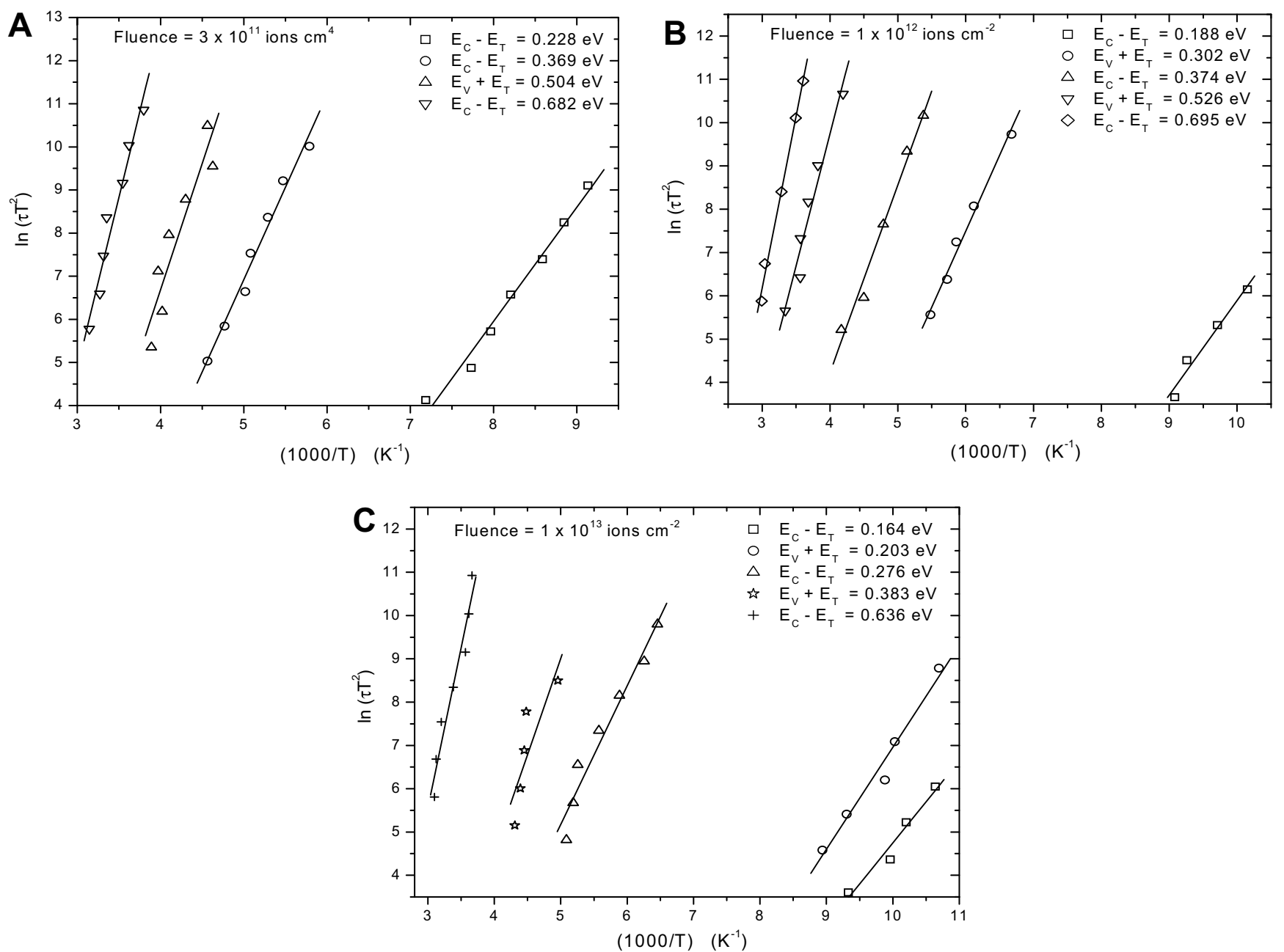

Fig. 10. Arrhenius plots for Cu-ion fluences: (A) $3 \times 10^{11}$ ions $\mathrm{cm}^{-2}$; (B) $1 \times 10^{12}$ ions $\mathrm{cm}^{-2}$; (C) $1 \times 10^{13}$ ions cm $\mathrm{cm}^{-2}$. 
types of defects such as vacancy, interstitial, di-vacancy, Frenkel pair, vacancy-impurity complexes namely A-center (V-O), E-center $(\mathrm{V}-\mathrm{P})$, interstitial clusters and di-interstitial or higher order complexes called D-center [11].

The deep level defects generated by irradiation of transistors by $\mathrm{Cu}$-ions are characterized using DLTS technique. Fig. 9 exhibits the DLTS spectra of $\mathrm{Cu}$-ion irradiated transistor for three different ion fluences. Fig. 10 exhibits the Arrhenius plots of deep level defects for three different ion fluences. Three minority carrier and one majority carrier deep level defects are observed in the DLTS spectra of the $\mathrm{Cu}$-ion irradiated transistor with fluence of $3 \times 10^{11}$ ions $\mathrm{cm}^{-2}$. For the ion fluences $1 \times 10^{12}$ and $1 \times 10^{13}$ ions $\mathrm{cm}^{-2}$, three minority carrier and two majority carrier defect levels are observed. The trap concentration, capture crosssection and introduction rate of all the deep level defects are calculated from the DLTS spectra and presented in Table 1.

Recombination of electron-hole pairs at the defect levels generated upon displacement damage is the most important physical phenomenon responsible for the gain degradation. Mainly four kinds of recombination processes are observed in semiconductor devices: (i) Shockley Read Hall (SRH) or multi-phonon recombination; (ii) radiative recombination; (iii) Auger recombination and (iv) non-radiative recombination. Radiative recombination is important in direct band gap semiconductors like GaAs. Auger recombination is observed in either direct or indirect band gap semiconductors when the carrier concentration is high. Further, the radiative, non-radiative and Auger recombination lifetimes are independent of trap concentration [13]. SRH recombination is particularly important in indirect band gap semiconductors such as $\mathrm{Si}$ [13-17]. The values of SRH recombination lifetimes calculated using DLTS data are tabulated in Table 1.

The transistor irradiated with fluence $1 \times 10^{12}$ ions $\mathrm{cm}^{-2}$ is subjected to both isothermal and isochronal annealing and the characteristics of each defect are monitored by recording DLTS spectra. However, no significant changes are observed in the DLTS spectra as a function of annealing time at a given constant temperature (isothermal annealing). After isochronal annealing, significant changes are observed in the DLTS spectra. The total defect concentration decreases and the effective recombination life time increases with an increase in isochronal (30 min) annealing temperature as shown in Fig. 11. Fig. 12 exhibits the variation of concentration of different deep level defects as a function of isochronal (30 $\mathrm{min}$ ) annealing temperature. The annealing behavior of different deep level defects in silicon has been studied by several

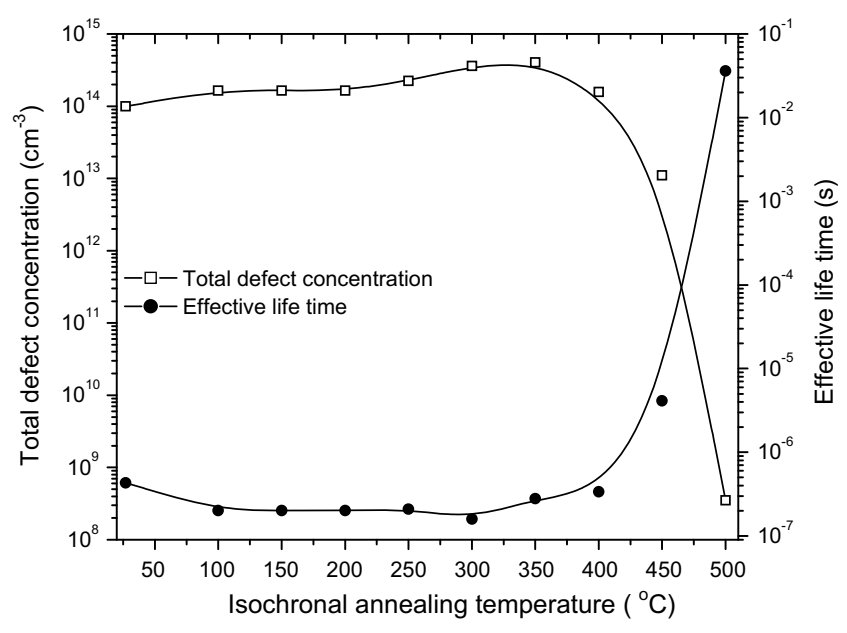

Fig. 11. Variation of total defect concentration and effective recombination life time as a function of isochronal annealing temperature.

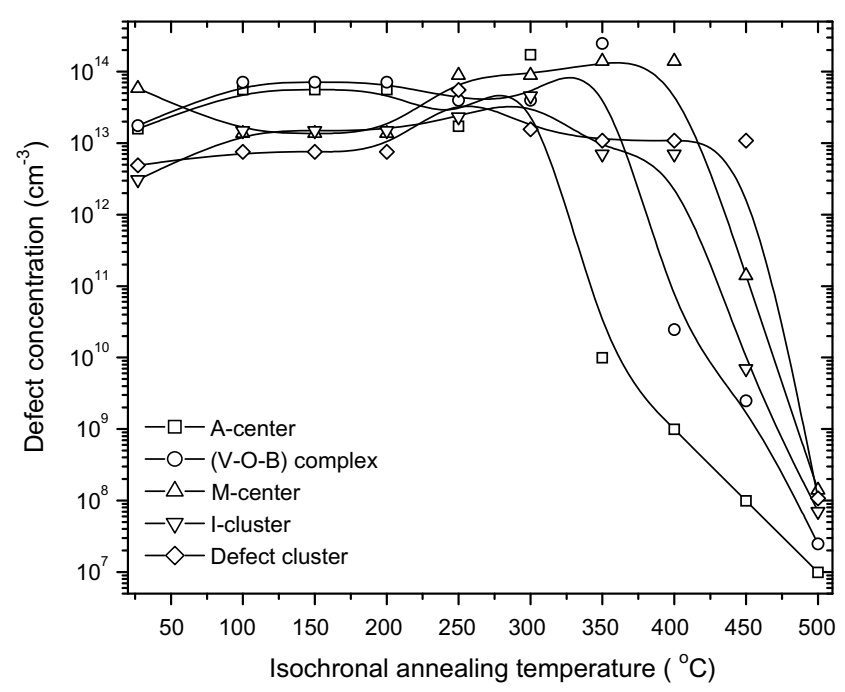

Fig. 12. Variation of defect concentration as a function of isochronal annealing temperature.

Table 1

Data obtained from DLTS analysis of the $\mathrm{Cu}$-ion irradiated transistor

\begin{tabular}{|c|c|c|c|c|c|c|c|c|c|}
\hline \multirow{2}{*}{$\begin{array}{l}\text { Ion fluence } \\
\text { (ions } \mathrm{cm}^{-2} \text { ) }\end{array}$} & \multirow{2}{*}{$\begin{array}{l}\text { Defect } \\
\text { label }\end{array}$} & \multirow{2}{*}{$\begin{array}{l}\text { Activation energy } \\
(\mathrm{eV})\end{array}$} & \multirow{2}{*}{$\begin{array}{l}\text { Trap } \\
\text { concentration } \\
\left(\mathrm{cm}^{-3}\right)\end{array}$} & \multirow{2}{*}{$\begin{array}{l}\text { Capture cross-section } \\
\left(7 \times 10^{-18} \mathrm{~cm}^{2}\right)\end{array}$} & \multirow{2}{*}{$\begin{array}{l}\text { Introduction } \\
\text { rate } \eta\left(\mathrm{cm}^{-1}\right)\end{array}$} & \multirow{2}{*}{$\begin{array}{l}\text { Recombination } \\
\text { life time (s) }\end{array}$} & \multirow{2}{*}{$\begin{array}{l}\text { Identified } \\
\text { defect type }\end{array}$} & \multicolumn{2}{|c|}{ Literature comparison } \\
\hline & & & & & & & & $\begin{array}{l}\text { Defect } \\
\text { position }\end{array}$ & Reference \\
\hline $3 \times 10^{11}$ & $\begin{array}{l}\text { ES31 } \\
\text { ES32 } \\
\text { HS31 } \\
\text { ES33 }\end{array}$ & $\begin{array}{l}E_{\mathrm{C}}-0.228 \pm 0.018 \\
E_{\mathrm{C}}-0.369 \pm 0.019 \\
E_{\mathrm{V}}+0.504 \pm 0.044 \\
E_{\mathrm{C}}-0.682 \pm 0.030\end{array}$ & $\begin{array}{l}4.5 \times 10^{12} \\
2.0 \times 10^{13} \\
9.3 \times 10^{12} \\
2.2 \times 10^{12}\end{array}$ & $\begin{array}{l}2.3 \times 10^{-15} \\
1.1 \times 10^{-15} \\
9.8 \times 10^{-15} \\
8.8 \times 10^{-14}\end{array}$ & $\begin{array}{r}15.1 \\
65.8 \\
31.0 \\
7.3\end{array}$ & $\begin{array}{l}1.3 \times 10^{-05} \\
4.8 \times 10^{-06} \\
1.1 \times 10^{-06} \\
4.4 \times 10^{-07}\end{array}$ & $\begin{array}{l}\text { Di-vacancy } \\
\left(\mathrm{C}_{\mathrm{i}}-\mathrm{O}_{\mathrm{i}}\right) \\
\text { I-cluster } \\
\text { Cluster }\end{array}$ & $\begin{array}{l}E_{\mathrm{C}}-0.23 \\
E_{\mathrm{C}}-0.36 \\
E_{\mathrm{V}}+0.50 \\
-\end{array}$ & $\begin{array}{l}{[21]} \\
{[21]} \\
{[25]} \\
-\end{array}$ \\
\hline $1 \times 10^{12}$ & $\begin{array}{l}\text { ES41 } \\
\text { HS41 } \\
\text { ES42 } \\
\text { HS42 } \\
\text { ES43 }\end{array}$ & $\begin{array}{c}E_{\mathrm{C}}-0.188 \pm 0.031 \\
E_{\mathrm{V}}+0.302 \pm 0.018 \\
E_{\mathrm{C}}-0.340 \pm 0.020 \\
E_{\mathrm{V}}+0.526 \pm 0.029 \\
E_{\mathrm{C}}-0.695 \pm 0.017\end{array}$ & $\begin{array}{l}1.6 \times 10^{13} \\
1.8 \times 10^{13} \\
5.8 \times 10^{13} \\
3.1 \times 10^{12} \\
4.9 \times 10^{12}\end{array}$ & $\begin{array}{l}4.6 \times 10^{-15} \\
4.2 \times 10^{-16} \\
2.8 \times 10^{-16} \\
1.3 \times 10^{-15} \\
2.7 \times 10^{-14}\end{array}$ & $\begin{array}{r}15.9 \\
17.6 \\
57.8 \\
3.1 \\
4.9\end{array}$ & $\begin{array}{l}2.0 \times 10^{-06} \\
1.6 \times 10^{-05} \\
6.5 \times 10^{-06} \\
2.2 \times 10^{-05} \\
6.4 \times 10^{-07}\end{array}$ & $\begin{array}{l}\text { A-center } \\
\text { (V-O-B) } \\
\text { M-center } \\
\text { I-cluster } \\
\text { Cluster }\end{array}$ & $\begin{array}{l}E_{\mathrm{C}}-0.18 \\
E_{\mathrm{V}}+0.30 \\
E_{\mathrm{C}}-0.33 \\
E_{\mathrm{V}}+0.50 \\
-\end{array}$ & $\begin{array}{l}{[26]} \\
{[27]} \\
{[28]} \\
{[25]} \\
-\end{array}$ \\
\hline $1 \times 10^{13}$ & $\begin{array}{l}\text { ES21 } \\
\text { HS21 } \\
\text { ES22 } \\
\text { HS22 } \\
\text { ES23 }\end{array}$ & $\begin{array}{r}E_{\mathrm{C}}-0.164 \pm 0.030 \\
E_{\mathrm{V}}+0.203 \pm 0.026 \\
E_{\mathrm{C}}-0.276 \pm 0.023 \\
E_{\mathrm{V}}+0.383 \pm 0.071 \\
E_{\mathrm{C}}-0.636 \pm 0.030\end{array}$ & $\begin{array}{l}1.6 \times 10^{13} \\
1.0 \times 10^{14} \\
2.4 \times 10^{12} \\
1.7 \times 10^{13} \\
3.0 \times 10^{14}\end{array}$ & $\begin{array}{l}8.5 \times 10^{-16} \\
9.0 \times 10^{-15} \\
3.6 \times 10^{-17} \\
3.0 \times 10^{-16} \\
9.0 \times 10^{-15}\end{array}$ & $\begin{array}{r}1.6 \\
10.1 \\
0.2 \\
1.7 \\
30.4\end{array}$ & $\begin{array}{l}1.2 \times 10^{-05} \\
1.6 \times 10^{-07} \\
1.6 \times 10^{-03} \\
2.0 \times 10^{-05} \\
3.2 \times 10^{-08}\end{array}$ & $\begin{array}{l}\text { A-center } \\
\text { Di-vacancy } \\
\left(\mathrm{B}_{\mathrm{i}}-\mathrm{O}_{\mathrm{i}}\right) \\
\text { K-center } \\
\text { Cluster }\end{array}$ & $\begin{array}{l}E_{\mathrm{C}}-0.17 \\
E_{\mathrm{V}}+0.21 \\
E_{\mathrm{C}}-0.27 \\
E_{\mathrm{V}}+0.38 \\
-\end{array}$ & $\begin{array}{l}{[25]} \\
{[25]} \\
{[27]} \\
{[27]} \\
-\end{array}$ \\
\hline
\end{tabular}


groups and documented well in the literature [18-24]. The identification of the defect type is made on the basis of their finger prints such as activation energy, annealing temperature and capture cross section. Table 1 shows the assignment of defect types with activation energy and the comparison with the reported values in the literature. The error margins in the activation energy and capture cross-section are also shown.

The defect levels $E_{\mathrm{C}}-0.682, E_{\mathrm{C}}-0.695$ and $E_{\mathrm{C}}-0.636$ anneal at $500{ }^{\circ} \mathrm{C}$. By comparing the measured properties of these levels with those reported in the literature, these levels could be attributed to new energy levels of defect clusters in silicon.

A comparison of $I-V$ characteristics (Figs. 4-6), $C-V$ characteristics (Fig. 8) and DLTS results (Figs. 11 and 12) before and after annealing suggests that the defects which annihilate in the temperature range $350{ }^{\circ} \mathrm{C}$ to $500{ }^{\circ} \mathrm{C}$ have a major contribution to the change in the base and collector currents and hence degradation of the forward current gain of the transistor.

One other important observation in the present investigation is that the nature of the defects varies with increasing radiation dose. The different type of defects that appear after irradiation with different fluence is not only interesting but is rather unusual. Similar variations have been observed in our earlier studies and are also reported earlier by others [29]. On the contrary, it is well reported in the literature that A-center $(\mathrm{O}-\mathrm{V})$ is the first defect that appears in most Si structures after irradiation [30,31]. In the present study, we have not observed A-center for a fluence of $3 \times 10^{11}$ ions $\mathrm{cm}^{-2}$. However, for higher fluences, this defect type appears in the DLTS spectra. One possible reason for this observation is that irradiation at higher fluence may result in saturation of defects and defect reordering which occurs due to the interaction between the existing defects and newly formed defects. The nature of defect could also change due to concentration of species. For example, either vacancy combination or di-vacancy combination might be favored depending upon the concentration of combining species. A gradual variation in the particle fluence and subsequent monitoring of defect levels would be useful in the identification and assignment of defect types.

DLTS monitors the thermally activated emissions, unlike in optical spectroscopy. Hence, the assignment of DLTS peaks to exact nature and type of defects could be difficult. To identify the exact microscopic structure of these defect levels, investigation by other structure sensitive techniques such as electron paramagnetic resonance (EPR) and infrared photoconductivity measurements would be required.

\section{Conclusions}

Commercial bipolar junction transistor (2N 2219A, npn) undergoes gain degradation upon irradiation by $\mathrm{Cu}^{11+}$-ions. The gain degradation can be attributed to displacement damage in the base region of the transistor. Deep level defects generated in the collector-base junction of the transistor are identified as electron traps with activation energies ranging from $E_{\mathrm{C}}-0.164 \mathrm{eV}$ to $E_{\mathrm{C}}-0.695 \mathrm{eV}$ and hole traps with activation energies from $E_{\mathrm{V}}+0.203 \mathrm{eV}$ to $E_{\mathrm{V}}+0.526 \mathrm{eV}$. DLTS studies made after annealing show that most of the defects anneal out above a temperature of $350{ }^{\circ} \mathrm{C}$. The defects generated in the base region of the transistor by displacement damage appear to be responsible for an increase in base current through SRH or multi-phonon recombination and consequent transistor gain degradation.

\section{Acknowledgements}

Authors thank Mr. R.N. Dutt of IUAC, New Delhi, for his help during the experiments conducted at IUAC. One of the author
(K.V Madhu) thanks UGC-IUAC for a fellowship to carry out the present work. Financial support in the form of ISRO-RESPOND research project is acknowledged. The authors thank Dr. V. Pandian of $\mathrm{M} / \mathrm{s}$. Lab Equip. for many helpful discussions.

\section{References}

[1] Schmidt DM, Fleetwood DM, Schrimf RD, Pease RL, Graves RJ, Johnson GH, et al. Comparison of ionizing-radiation-induced gain degradation in lateral, substrate, and vertical PNP BJTs. IEEE Trans Nucl Sci 1995;42(6): 1541-9.

[2] Raymond JP, Petersen EL. Comparison of neutron, proton and gamma ray effects in semiconductor devices. IEEE Trans Nucl Sci 1987;NS34(6):1622-8

[3] Summers GP, Wolicki EA, Xapsos MA, Marshall P, Dale CJ, Gehlhauen MA, et al. Energy dependence of proton displacement damage factors for bipolar transistors. IEEE Trans Nucl Sci 1986;NS-33(6):1282-6.

[4] Nichols DK, Price WE, Gauthier MK. A comparison of radiation damage in transistors from cobalt-60 gamma rays and $2.2 \mathrm{MeV}$ electrons. IEEE Trans Nucl Sci 1982;NS-29(6):1970-4

[5] Dale CJ, Marshall PW, Burke EA, Summers GP, Wolicki EA. High energy electron induced displacement damage in silicon. IEEE Trans Nucl Sci 1988;35(6):1208-14.

[6] Lang DV. Deep-level transient spectroscopy: a new method to characterize traps in semiconductors. J Appl Phys 1974;45(7):3023-32.

[7] Kulkarni SR, Sharma A, Joshi GR, Ravindra M, Damle R. Proton and gamma ray induced gain degradation in bipolar transistor. Radiat Eff Defects Solids 2003;158:647-54.

[8] Kulkarni SR, Ravindra M, Joshi GR, Damle R. Simulation of energy and fluence dependence of heavy ion induced displacement damage factor in bipolar junction transistor. Radiat Eff Defects Solids 2004;159:273-80.

[9] Kulkarni SR, Ravindra M, Joshi GR, Damle R. High-energy electron induced gain degradation in bipolar junction transistors. Nucl Instrum Methods B 2006;251:157-62.

[10] Madhu KV, Kulkarni SR, Ravindra M, Damle R. DLTS study of deep level defects in Li-ion irradiated bipolar junction transistor. Nucl Instrum Methods B 2007;254:98-104.

[11] Srour JR, Cheryl JM, Marshall PW. Review of displacement damage effects in silicon devices. IEEE Trans Nucl Sci 2003;50(3):653-70.

[12] Brotherton SD, Bradley P. Defect production and lifetime control in electron and $\gamma$-irradiated silicon. J Appl Phys 1982;53(8):5720-32.

[13] Schroder DK. Semiconductor material and device characterization. John Wiley \& Sons; 1990. p. 309 and p. 361-2.

[14] Watanabe K, Munakata C. Recombination lifetime in a gold doped p-type silicon crystal. Semicond Sci Technol 1993:8:230-5.

[15] Hangleiter A. Nonradiative recombination via deep impurity levels in silicon: experiment. Phys Rev B 1987;35(17):9149-61.

[16] Shockley W, Read WT. Statistics of the recombinations of holes and electrons. Phys Rev 1952;87(5):835-43.

[17] Khanna VK. Carrier lifetimes and recombination-generation mechanisms in semiconductor device physics. Eur J Phys 2004;25:221-37.

[18] Libertino S, Coffa S, Benton JL. Formation, evolution, and annihilation of interstitial clusters in ion-implanted Si. Phys Rev B 2001;63:1952061-195206-14.

[19] Khan A, Yamaguchi M, Ohshita Y, Dharmarasu N, Araki K, Abe T, et al. Role of the impurities in production rates of radiation-induced defects in silicon materials and solar cells. J Appl Phys 2001;90(3):1170-8.

[20] Walker JW, Sah CT. Properties of 1.0-MeV-electron-irradiated defect centers in silicon. Phys Rev B 1973;7(10):4587-605.

[21] Pellegrino P, Leveque P, Lalita J, Hallen A, Jagadish C, Svensson BG. Annealing kinetics of vacancy-related defects in low-dose MeV self-ion-implanted n-type silicon. Phys Rev B 2001;64:195211-1-1-9.

[22] Chantre A, Kimerling LC. Configurationally multistable defect in silicon. Appl Phys Lett 1986;48(15):1000-2.

[23] Schmidt DC, Svensson BG, Lindstrom JL, Godey S, Ntsoenzok E, Barbot JF, et al. $2 \mathrm{MeV}$ electron irradiation of silicon at elevated temperatures: influence on platinum diffusion and creation of electrically active defects. J Appl Phys 1999;85(7):3556-60.

[24] Yapsir AS, Hadizad P, Lu TM, Corelli JC, Corbett JW, Lanford WA, et al. Defect centers and changes in the electrical characteristics of $\mathrm{Al} / \mathrm{n}$-type Si Schottky diodes induced by hydrogen-ion implantations. Phys Rev B 1988;37(15):8982-7.

[25] Benton JL, Libertino S, Kringhoj P, Eaglesham DJ, Poate JM, Coffa S. Evolution from point to extended defects in ion implanted silicon. J Appl Phys 1997;82(1):120-5.

[26] Svensson BG, Jagadish C, Hallen A, Lalita J. Generation of vacancy-type defects in single collision cascades during swift-ion bombardment of silicon. Phys Rev B 1997;55(16):10498-507.

[27] Mooney PM, Cheng LJ, Suli M, Gerson JD, Corbett JW. Defect energy levels in boron-doped silicon irradiated with $1-\mathrm{MeV}$ electrons. Phys Rev B 1977; 15(8):3836-43.

[28] Schmidt DC, Svensson BG, Seibt M, Jagadish C, Davies G. Photoluminescence, deep level transient spectroscopy and transmission electron microscopy 
measurements on MeV self-ion implanted and annealed n-type silicon. J Appl Phys 2000;88(5):2309-17.

[29] Gnana Prakash AP, Ke SC, Siddappa K. Swift heavy ion irradiation effects on electrical and defect properties of NPN transistors. Semicond Sci Technol 2004;19:1029-39.
[30] Libertino S, Benton JL, Coffa S, Jacobson DC, Eaglesham D, Poate JM. The effect of extra ion on residual damage in $\mathrm{MeV}$ implanted Si. Mater. Res. Soc. Symp. Proc. 1997;469:187-92.

[31] Brotherton SD, Bradley P. Defect production and lifetime control in electron and $\gamma$-irradiated silicon. 1992;53:5720-32. 